\title{
Comparison of immunohistochemistry (IHC) and fluorescence in situ hybridization (FISH) assessment for Her-2 status in breast
}

\section{cancer}

\author{
Weiguo Sui ${ }^{\dagger 1}$, Minglin Ou ${ }^{\dagger 1,2}$, Jiejing Chen ${ }^{\dagger 1}$, Youhua Wan ${ }^{\dagger 3}$, \\ Hongbo Peng ${ }^{\dagger 1}$, Minfang $\mathrm{Qi}^{\dagger 3}$, He Huang ${ }^{\dagger 1}$ and Yong Dai*1
}

\begin{abstract}
Address: ${ }^{1}$ Laboratory Center of Guangzhou Military Area Command, 181st Hospital of People's Liberation Army, Guilin, Guangxi, PR China, ${ }^{2}$ College of Life Science, Guangxi Normal University, Guilin, Guangxi, PR China and 3Pathology Department of Guangzhou Military Area Command, 181st Hospital of People's Liberation Army, Guilin, Guangxi, PR China

Email: Weiguo Sui - suiwg@163.com; Minglin Ou - ouminglin@yahoo.com.cn; Jiejing Chen - jiejingchen@126.com; Youhua Wan -wyhsa@tom.com; Hongbo Peng - gongxi20070515@126.com; Minfang Qi - omegacyh@163.com;

He Huang - yellowriver0122@163.com; Yong Dai* - daiyong22@yahoo.com.cn

* Corresponding author †Equal contributors
\end{abstract}

Published: 9 November 2009

World Journal of Surgical Oncology 2009, 7:83 doi:10.1186/1477-7819-7-83

This article is available from: http://www.wjso.com/content/7///83

(c) 2009 Sui et al; licensee BioMed Central Ltd.

This is an Open Access article distributed under the terms of the Creative Commons Attribution License (http://creativecommons.org/licenses/by/2.0), which permits unrestricted use, distribution, and reproduction in any medium, provided the original work is properly cited.

\begin{abstract}
Background: The concordance rate between IHC and FISH according to clinical performance is still controversial. We report a prospective study to reflect the concordance between IHC and FISH in Guilin city, People's Republic of China.

Methods: Fifty cases of invasive ductal carcinoma of breast tested by $\mathrm{IHC}$ and scored as $0,1+, 2+$ and $3+$ by pathologists were further analyzed by FISH using a commercially available double-color probe, and the FISH findings were compared with IHC test results.

Results: A total concordance of $82.0 \%$ was observed with a Kappa coefficient of $0.640(P<0.00 I)$. A high discordance was observed in $30.0 \%$ of the patients with $\mathrm{IHC} 2+, 7.1 \%$ in $\mathrm{IHC} 3+, 19.2 \%$ overall in $\mathrm{IHC} 0$ and $\mathrm{I}+$.

Conclusion: The IHC can be used firstly to screen the HER-2 status, and FISH can be used as a supplementary role to $\mathrm{IHC}$ and $2+$ and some negative cases. And only those cases with Her-2 status of IHC $3+$ or FISH positive should be treated with Herceptin.
\end{abstract}

\section{Background}

Breast cancer is one of the most common malignancy in the world. According to the global cancer statistics, Europe and America has the high incidence and mortality of breast cancer [1]. The incidence of breast cancer in China is 20 per 100,000 population, and the incidence is growing [2]. Researches have shown that about $20 \%-30 \%$ of the breast cancer patients have Her- 2 amplification or over expression, that is associating with a more aggressive phenotype and decreased survival [3-7]. The benefit of humanized anti-Her-2 monoclonal antibody trastuzumab (Herceptin) in Her-2-positive breast cancers has been well documented as noted by prolonged survival [8]. But this therapy is effective only if the detection of Her-2 status is accurate.

There are several methods available to detect the Her-2 status like polymerase chain reaction (PCR), immunohis- 
tochemistry (IHC), fluorescence in situ hybridization (FISH), chromogenic in situ hybridisation (CISH) $[9,10]$. Protein over-expression detected by IHC or amplification of Her- 2 gene analyzed by FISH are the two main methods used to detect Her-2 status in clinical practice. FISH is considered as a gold standard because of its sensitivity and specificity. But FISH has disadvantages as it requires a modern and expensive fluorescence microscope equipped with multi-band-pass fluorescence filters, and the fluorescence fades so quickly that it could not provide a permanent record [10]. Compared with FISH, IHC is widely used in china as it is cheaper and convenient to operate and conserve; the morphology is clear. Comparative studies of IHC and FISH have generally shown a high concordance rate by some researches [11]. But protein overexpression may be found without gene amplification or gene amplification can be found in negative IHC [12]. Research has documented that the discordance rate between Her-2 by FISH and IHC is high in all four IHC scores $(0,1+, 2+, 3+)$, and a FISH-alone screening strategy has been alternatively suggested [13]. Our objective was to perform a prospective study in our own local setting and record the concordance between IHC and FISH in 50 cases of invasive ductal carcinoma of breast.

\section{Methods \\ Study Design}

The study population consists of 50 cases of invasive ductal carcinoma of breast treated between July, 2008 and March, 2009 at The 181 Hospital and Traditional Chinese Medicine Hospital which are the two main hospitals for the treatment of breast cancer in Guilin city of China. The specimens were fixed in $10 \%$ neutral-buffered formalin (pH7.4) for 24 hours. Only cases with sufficient invasive carcinoma for multiple assays were included in the study. For each case, 2-4 $\mu \mathrm{m}$ thick tissue sections were cut from a representative paraffin block and applied to positively charged slides. Her-2 protein expression was measured using a commercial available S-P kit. FISH for Her-2 gene amplification was performed in the key laboratory of 181 Hospital using a commercial available double-color probe. The interpretation of IHC and FISH were each performed by investigators blinded to the results of the other assay

\section{IHC analysis}

IHC study was performed on paraffinem-bedded, formalin-fixed tissue sections using a commercial available Ultra Sensitive $^{\mathrm{TM}}$ S-P kit (Maixin-Bio Co., Fuzhou, China), following the manufacturer's instructions and American Society of Clinical Oncology/College of American Pathologists guideline recommendations for human Epidermal Growth Factor Receptor 2 testing in breast cancer [14]. Briefly, this procedure included the deparaffinization and rehydration steps, followed by an epitope retrieval step in which the tissue sample was incubated in a citrate buffer solution at $90-95^{\circ} \mathrm{C}$ for 20 minutes. The slides were then subjected to a series of alternating washes in tris (hydroxymethyl) aminomethane hydrochloride buffer and incubation steps with, first, a peroxidase-blocking reagent for 5 minutes and then with Her-2 primary antibody, followed by a visualization reagent for 30 minutes each, and finally with a 3,3'-diaminobenzidine chromogen solution. After a finally wash, the slides were counterstained with haematoxylin [15].

Tumor cells with circumferential membranous positivity were considered as Her-2 protein over expression, and scoring was performed according to the manufacturer's recommendations by pathologists in a number of different practice groups (Figure 1), each with at least 10 years of experience in clinical practice; in order to truly reflect the concordance or discordances between IHC and FISH in our daily practices, the results of IHC were all from the data bank of the two hospitals and without revision again.

\section{FISH for Her-2 gene amplification}

FISH analysis was modified in cooperation with the manufacturer of China Medical Technologies, Inc. (Beijing, China). The commercially available double-color FISH probe consisted of two probes: 17q11.2-q12 (labeled with Spectrum Orange) covering the whole Her-2 gene and the control, centromeric chromosome 17p11.1-q11.1 (labeled with Spectrum Green). The FISH fixed glass microscope slides with tissue sections were baked overnight at $65^{\circ} \mathrm{C}$, deparaffinized in two 10 -minute changes of xylene, transferred through two 3-minute changes of $100 \%$ ethanol, one 3-minute changes of $85 \%$ ethanol, one 3-minute changes of $70 \%$ ethanol and immersed for 15 minutes in pure water at $90^{\circ} \mathrm{C}$. The slides were then incubated for 7-15 minutes in protease solution at $37^{\circ} \mathrm{C}$. Then the slides were briefly washed in $2 \times$ sodium saline citrate $(2 \times$ SSC; $\mathrm{pH} 7.2)$ at room temperature, dehydrated through $70 \%, 85 \%, 100 \%$ ethanol and acetone, then allowed to air dry. To denature DNA, the slides were placed in $78.5^{\circ} \mathrm{C}$ preheated $70 \%$ formamide $/ 2 \times$ SSC for 8 min and then dehydration in a graded series of concentrations of ethanol which were precooling in $-20^{\circ} \mathrm{C}$. After drying in the open-air, $10 \mu \mathrm{l}$ of probe which was destructured at $75.5^{\circ} \mathrm{C}$ for $7 \mathrm{~min}$ was applied onto each slide, cover slip was placed and sealed with rubber cement, then hybridized overnight at $42.8^{\circ} \mathrm{C}$. After $16-18 \mathrm{~h}$ of hybridization, the slides were washed in $46^{\circ} \mathrm{C}$ preheated posthybridization buffer $(2 \times \mathrm{SSC} / 0.1 \%$ sodium dodecyl sulfate) for $5 \mathrm{~min}$ and rinsed in $70 \%$ ethanol. After air-drying (out of direct light), the slides were counterstained with $15 \mu \mathrm{L}$ DAPI/anti-fade solution and cover slip applied.

FISH analysis was performed by two cytotechnologistes who were blinded to the clinical diagnoses at the time of 


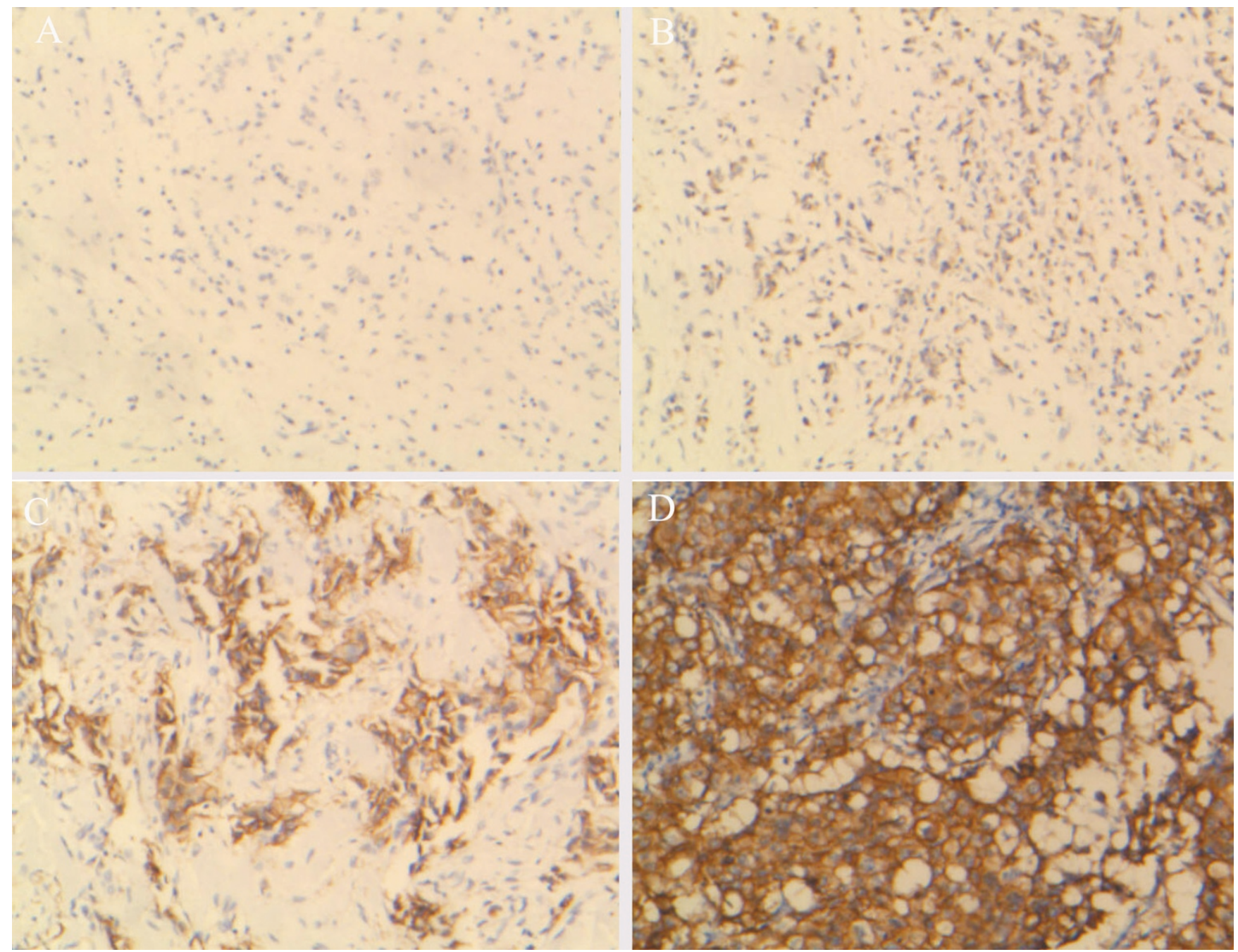

\section{Figure I}

IHC for Her-2 protein expression. Figure I (A) Completely negative, IHC0; (B) Faint membranous positivity, ICHI+; (C) Moderate membranous positivity, IHC2+; (D)Strong, more than 30\% tumor cells with circumferential membranous positivity, $\mathrm{IHC3+}$.

evaluation. The slides were scanned using a OLYMPUS BX51 fluorescent microscope (OLYMPUS BX51, Japan) equipped with a 100-watt mercury lamp and single band pass filter set to detect DAPI, Rhodamine (17q11.2-q12), and FITC (chromosome 17) at 1000x. Thirty randomly selected invasive tumor nuclei in each of two separate, distinct microscopic areas were evaluated. Cases were scored as negative by FISH when the Her- 2 with a Her- 2 to CEP 17 ratio $<1.8$ by counting at least 30 interphase nuclei, and those cases with a Her- 2 to CEP 17 ratio $>2.2$ were scored as positive (Figure 2). In addition, more randomly selected invasive tumor nuclei (for example, a total of 100 nuclei) would be evaluated if the Her- 2 with a Her- 2 to CEP 17 ratio was between 1.8 and 2.2.

\section{Results}

Of the 50 specimens in our study (invasive ductal carcinoma with varying tumor grades and clinical stages), 9 were classified as IHC 0,17 were classified as IHC $1+, 10$ were classified as IHC $2+$, and 14 were classified as IHC $3+$. Five of the IHC 0 and $1+$ cases, seven of the 10 IHC $2+$ cases and 13 of the 14 IHC $3+$ cases were found to be Her2 FISH positive. They had a total concordance of $82.0 \%$ and a Kappa coefficient of $0.640(\mathrm{P}<0.001)$, which was defined as IHC $2+/ 3+$ and Her- 2 FISH positive, or IHC $0 /$ $1+$ and Her-2 FISH negative.

Discordance was defined as a discrepancy between the IHC and Her-2 FISH, including the following two conditions: (1) IHC $2+$ or $3+$ but Her-2 FISH negative; (2) IHC 

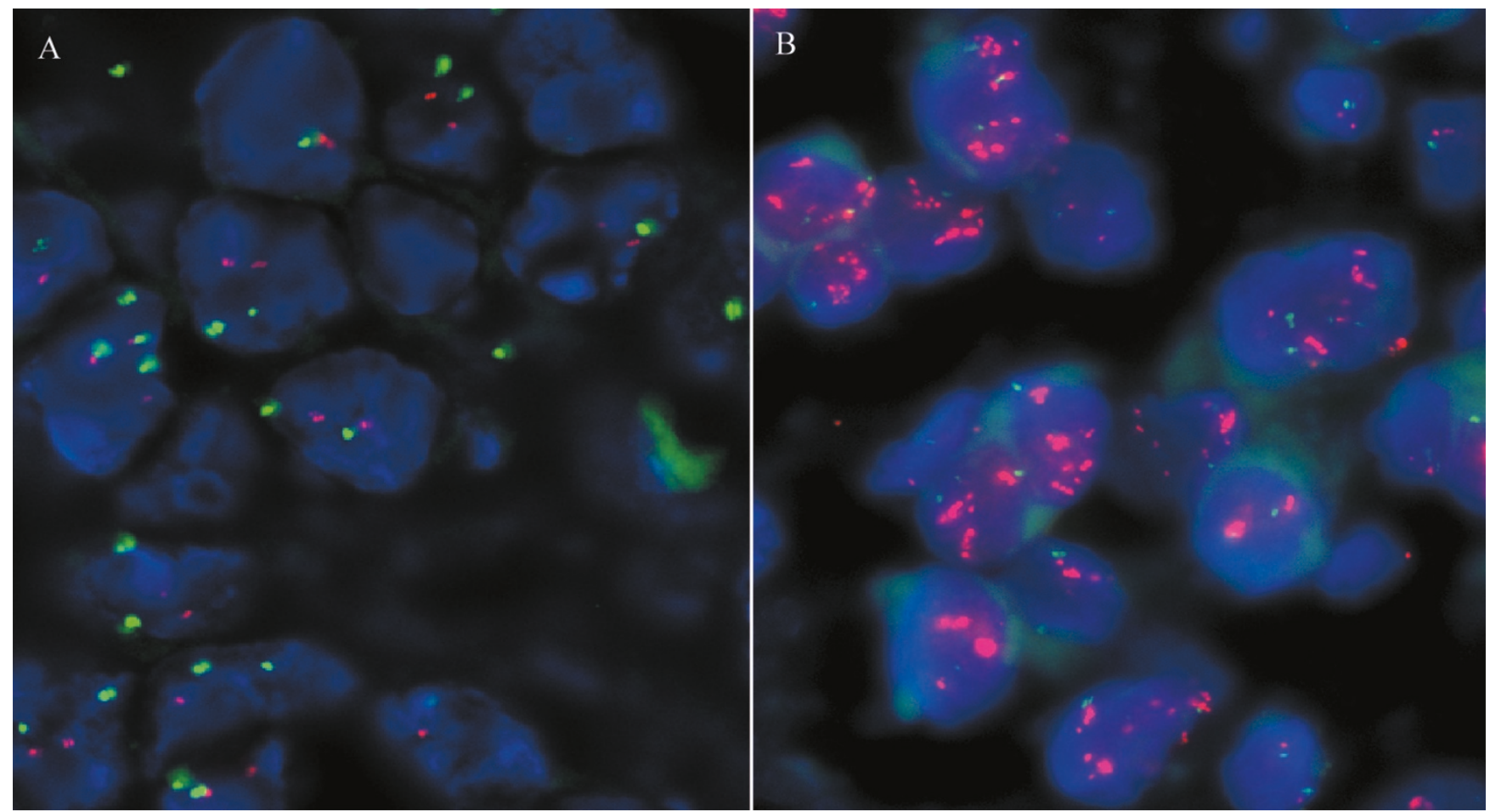

Figure 2

FISH for Her-2 gene amplification. Figure 2 (A) Negative amplification of human epidermal growth factor receptor-2/neu (Her-2) gene case with the ratio of Her-2 (red signals) to CEP I7 (green signals) is obviously smaller than I.8; (B) Positive amplification of human epidermal growth factor receptor-2/neu (Her-2) gene case with the ratio of Her-2 (red signals) to CEP 17 (green signals) is obviously larger than 2.2 .

0 or $1+$ but Her- 2 FISH positive. For example, the discordance rate according to IHC 0 and $1+$ was defined as the number of discrepant IHC 0 and $1+$ cases divided by the total number of IHC 0 and 1+ cases and was 19.2\% (5/ 26). Following the same way of counting, the discordance rate according to IHC $2+$ was $30.0 \%$ (3/10), IHC $3+$ was $7.1 \%(1 / 14)$. The overall discordance rate by IHC was therefore $18.0 \%(9 / 50)$ (Table 1$)$.

\section{Discussion}

Reliable laboratory data in evaluating Her-2 status is essential, because the treatment is beneficial for advanced breast cancer and can avoid potential cardiotoxic effects in women not showing amplification or overexpression [16]. Her-2 status studied at the levels of DNA using FISH and protein using IHC are the two most accessible and feasible methods used in clinical diagnosis, and certain kits or antibodies are approved by the FDA (U.S. Food and Drug Administration). IHC is easy to perform and relatively cheap, and is predominantly used to evaluate Her-2 status. However, a wide range of sensitivity and specificity has been observed among various commercially available antibodies [17]. As an alternative, FISH is also recognized as a modality in cases with an equivocal IHC status with higher sensitivity and specificity.

Considering FISH as a gold standard, research reports that positive FISH results could be found in $91.7 \%, 23.2 \%$, $7.4 \%$ and $4.1 \%$ in cases with IHC respectively diagnosed as $3+, 2+, 1+$ and 0 [18]. In addition, some clinical trials

Table I: Comparison of the results of IHC and FISH

\begin{tabular}{|c|c|c|c|c|}
\hline IHC scoring & Her-2 FISH amplified & Her-2 FISH non-amplified & Concordance by IHC & Discordance by IHC \\
\hline 0 and $I+(n=26)$ & 5 & 21 & $(2 \mathrm{l} / 26) 80.8 \%$ & $(5 / 26) 19.2 \%$ \\
\hline $2+(n=10)$ & 7 & 3 & $(7 / 10) 70.0 \%$ & $(3 / 10) 30.0 \%$ \\
\hline $3+(n=14)$ & 13 & I & $(13 / 14) 92.9 \%$ & $(\mathrm{I} / \mathrm{l} 4) 7.1 \%$ \\
\hline
\end{tabular}

$\mathrm{IHC}=$ immunohistochemistry; FISH = fluorescence in situ hybridization 
have shown that amplification by FISH is more predictive of response to trastuzumab than IHC $[12,19,20]$.

Our objective in this study was not to try and compare the sensitivity and specificity of these two tests (IHC and FISH). This study aimed to investigate the concordance and discordance rates between IHC and Her-2 FISH. Some similar studies adopting a similar strategy have been reported. Dolan and Snover found that the concordance between the IHC and FISH scores (defined as cases that were IHC negative/FISH nonamplified or IHC positive/ FISH amplified) was found in 35 cases $(27.1 \%)$ and discordance in 94 cases (72.9\%) [15]. Lan et al. used FISH to ascertain the prevalence of erb-b2 gene amplification in 221 cases of breast cancer specimens read as $2+$ in IHC analysis, and found $96(44.4 \%)$ cases were detected to be erb-b2 amplified [21]. Kuo et al. compared FISH and IHC in breast cancer patients and found that the discordance rates by IHC were high $(46.7 \%$ in IHC $2+, 16.7 \%$ in IHC $3+, 30.3 \%$ overall in IHC $2+$ or $3+$ ) [22]. All these researches indicated that the concordance between IHC and FISH is still controversial.

There are some factors leading to false IHC test results, including variability in tissue fixation and processing, variable sensitivity and specificity of commercially available antibodies, and differences in scoring criteria with considerable interobserver variability in interpretation of results [23]. Our study is trying to answer a simpler question about the concordance between IHC and FISH in our local setting in Guilin city of China, using some commercially available antibodies, which have not been approved by the FDA. Compared with some studies $[15,22,23]$, our concordance in the cases of IHC $3+$ is similar with theirs, but there are some differences in the cases of IHC $0,1+$, $2+$. The concordance in this study of IHC 0 and $1+$ is lower, and IHC 2+ is higher than theirs. This may due to the different sensitivity and specificity of the antibodies and probe used in this study. The different sensitivity and specificity of the antibodies and probe need to be further researched.

\section{Conclusion}

In order to improve the therapeutic effect of herceptin in Her-2-positive breast cancers, the current algorithm using FISH as a supplementary role to IHC $2+$ need to be modified according to this study in our setting. The IHC can be used firstly to screen the HER-2 status, and FISH can be used as a supplementary role to detect IHC and 2+ and some negative cases, especially those with a high tumour grades. And only those cases with Her-2 status of IHC 3+ or FISH positive are proposed to be treated with herceptin.

\section{Competing interests}

This work is supported by the funding of Ministry of Health, P. R. China (Funding NO. WKJ 2007-3-001).

\section{Authors' contributions}

WS carried out the studies design, helped to draft the manuscript. MO drafted the manuscript and participated in FISH analysis. JC and HP carried out FISH analysis. YW, MQ and HH carried out IHC analysis. YD conceived of the study, and participated in its design and coordination and helped to draft the manuscript. All authors read and approved the final manuscript.

\section{Acknowledgements}

We thank Xuefeng Shi of Guilin Traditional Chinese Medicine Hospital and Runqiang Wu of Guilin 18I hospital for their assistance in this work.

\section{References}

I. Parkin DM, Bray F, Ferlay J: Global cancer statistics, 2002. CA Cancer J Clin 2005, 55(2):74- 108.

2. Zheng Y, Li DL, Xiang YM, Li XJ: The status and trend of breast cancer incidence in Shanghai. J Surg Concepts Pract 200I, 6:219-221.

3. Paterson MC, Dietrich KD, Danyluk J, Paterson AH, Lees AW, Jamil $\mathrm{N}$, Hanson J, Jenkins $\mathrm{H}$, Krause BE, McBlain WA: Correlation between c-erbB-2 amplification and risk of recurrent disease in node-negative breast cancer. Cancer Res I99I, 5 I(2):556-67.

4. Seshadri R, Firgaira FA, Horsfall DJ, McCaul K, Setlur V, Kitchen P: Clinical significance of HER-2/neu oncogene amplification in primary breast cancer. The South Australian Breast Cancer Study Group. J Clin Oncol 1993, II(10): 1936-42.

5. Press MF, Pike MC, Chazin VR, Hung G, Udove JA, Markowicz M, Danyluk J, Godolphin W, Sliwkowski M, Akita R: Her-2/neu expression in node-negative breast cancer: direct tissue quantitation by computerized image analysis and association of overexpression with increased risk of recurrent disease. Cancer Res 1993, 53(20):4960-70.

6. Press MF, Bernstein L, Thomas PA, Meisner LF, Zhou JY, Ma Y, Hung G, Robinson RA, Harris C, El-Naggar A, Slamon DJ, Phillips RN, Ross JS, Wolman SR, Flom KJ: HER-2/neu gene amplification characterized by fluorescence in situ hybridization: poor prognosis in node-negative breast carcinomas. J Clin Oncol 1997, I 5(8):2894-904.

7. Ross JS, Fletcher JA: The HER-2/neu oncogene: prognostic factor, predictive factor and target for therapy. Semin Cancer Biol 1999, 9(2):125-38.

8. Dean-Colomb W, Esteva FJ: Her2-positive breast cancer: herceptin and beyond. Eur J Cancer 2008, 44( ( 8):2806- 12.

9. Tanner M, Gancberg D, Di Leo A, Larsimont D, Rouas G, Piccart MJ, Isola J: Chromogenic in situ hybridization: a practical alternative for fluorescence in situ hybridization to detect HER-2/ neu oncogene amplification in archival breast cancer samples. Am J Pathol 2000, 157(5): 1467-72.

10. Sáez A, Andreu FJ, Seguí MA, Baré ML, Fernández S, Dinarés C, Rey M: HER-2 gene amplification by chromogenic in situ hybridisation (CISH) compared with fluorescence in situ hybridisation (FISH) in breast cancer-A study of two hundred cases. Breast 2006, 15(4):519-27.

II. Reed W, Hannisdal E, Boehler PJ, Gundersen S, Host H, Nesland JM: The prognostic value of $\mathrm{p} 53$ and c-erb B-2 immunostaining is overrated for patients with lymph node negative breast carcinoma: a multivariate analysis of prognostic factors in 613 patients with a follow-up of 14-30 years. Cancer 2000, 88(4):804-13.

12. Pauletti G, Dandekar S, Rong H, Ramos L, Peng H, Seshadri R, Slamon $\mathrm{DJ}$ : Assessment of methods for tissue-based detection of the HER-2/neu alteration in human breast cancer: a direct comparison of fluorescence in situ hybridization and immunohistochemistry. J Clin Oncol 2000, 18(21):365I-64. 
13. Tubbs RR, Pettay JD, Roche PC, Stoler MH, Jenkins RB, Grogan TM: Discrepancies in clinical laboratory testing of eligibility for trastuzumab therapy: apparent immunohistochemical falsepositives do not get the message. J Clin Oncol 200I, 19(10):27|4-2I.

14. Wolff AC, Hammond EH, Schwartz JN, Hagerty KL, Allred DC, Cote RJ, Dowsett M, Fitzgibbons PL, Hanna WM, Langer A, McShane LM, Paik S, Pegram MD, Perez EA, Press MF, Rhodes A, Sturgeon C, Taube SE, Tubbs R, Vance GH, Vijver M, Wheeler TM, Hayes DF: American Society of Clinical Oncology/College of American Pathologists guideline recommendations for human epidermal growth factor receptor 2 testing in breast cancer. J Clin Oncol 2007, 25(I): I I8-45.

15. Dolan M, Snover D: Comparison of immunohistochemical and fluorescence in situ hybridization assessment of HER-2 status in routine practice. Am J Clin Pathol 2005, I23(5):766-70.

16. Keefe DL: Trastuzumab-associated cardiotoxicity. Cancer 2002, 95(7): $1592-600$.

17. Bempt I Vanden, Vanhentenrijk $V$, Drijkoningen $M$, Vandenberghe $P$, De WC: Real-time reverse transcription-PCR and fluorescence in-situ hybridization are complementary to understand the mechanisms involved in HER-2/neu overexpression in human breast carcinomas. Histopathology 2005, 46(4):43I-4I.

18. Owens MA, Horten BC, Da Silva MM: HER2 amplification ratios by fluorescence in situ hybridization and correlation with immunohistochemistry in a cohort of 6556 breast cancer tissues. Clin Breast Cancer 2004, 5(I):63-9.

19. Dybdal N, Leiberman G, Anderson S: Determination of HER2 gene amplification by fluorescence in situ hybridization and concordance with the clinical trials immunohistochemical assay in women with metastatic breast cancer evaluated for treatment with trastuzumab. Breast Cancer Res Treat 2005, 93(I):3-1I.

20. Mass RD, Press MF, Anderson S, Cobleigh MA, Vogel CL, Dybdal N, Leiberman G, Slamon DJ: Evaluation of clinical outcomes according to HER2 detection by fluorescence in situ hybridization in women with metastatic breast cancer treated with trastuzumab. Clin Breast Cancer 2005, 6(3):240-6.

21. Lan C, Liu JM, Liu TW, Hsu D, Liang S, Chen JR, Peng JW: Erb-b2 amplification by fluorescence in situ hybridization in breast cancer specimens read as $2+$ in immunohistochemical analysis. Am J Clin Pathol 2005, I 24(I):97-I02.

22. Kuo SJ, Wang BB, Chang CS, Chen TH, Yeh KT, Lee DJ, Yin PL, Chen $M$ : Comparison of immunohistochemical and fluorescence in situ hybridization assessment for HER-2/neu status in Taiwanese breast cancer patients. Taiwan J Obstet Gynecol 2007, 46(2):|46-5|.

23. Jacobs TW, Gown AM, Yaziji H, Barnes MJ, Schnitt SJ: HER-2/neu protein expression in breast cancer evaluated by immunohistochemistry. A study of interlaboratory agreement. $\mathrm{Am} J$ Clin Pathol 2000, I I 3(2):25 I-8.
Publish with Bio Med Central and every scientist can read your work free of charge

"BioMed Central will be the most significant development for disseminating the results of biomedical research in our lifetime. "

Sir Paul Nurse, Cancer Research UK

Your research papers will be:

- available free of charge to the entire biomedical community

- peer reviewed and published immediately upon acceptance

- cited in PubMed and archived on PubMed Central

- yours - you keep the copyright
BioMedcentral 